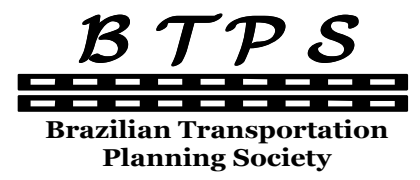
Journal of Transport Literature
Vol. 7, n. 3, pp. 177-191, Jul. 2013
Research Directory

\title{
Determinação do valor da tarifa-leilão do serviço de transporte de passageiros por ônibus: um modelo alternativo
}

[Setting up a price-cap for passenger coach service: an alternative model]

\author{
Paulo Augusto P. Britto*, Carlos Henrique Rocha \\ Universidade de Brasília (UnB) - Brazil
}

Submitted 14 Jun 2012; received in revised form 5 Dec 2012; accepted 27 Dec 2012

\begin{abstract}
Resumo
Este artigo oferece um método alternativo de precificação de tarifa do transporte de passageiros por ônibus. 0 modelo é implementável em situações de indisponibilidade de dados econômico-financeiros históricos por parte do regulador para estabelecer o rol de tarifas. 0 modelo apresentado se vale dos conceitos do modelo de regulação price-cap. Um coeficiente do tipo fator-X, no price-cap, é utilizado para a determinação da tarifa de forma a incentivar ganhos de produtividade. Esse fator é um índice de atividade da indústria de transporte de passageiros por ônibus ou da própria linha de ônibus. A literatura acadêmica de gestão financeira sugere diversos índices de atividade, sendo um deles a razão entre receita e ativo imobilizado líquido que é empregado nesse artigo. Por fim, o modelo é capaz de estabelecer o limite superior e o inferior para a tarifa-lance de forma a reduzir o espaço para comportamentos oportunistas por ocasião do leilão.
\end{abstract}

Palavras-Chave: tarifa do transporte de passageiros por ônibus, tarifa-leilão, preçco teto, fator-x, giro do imobilizado.

\begin{abstract}
This article offers an alternative method model for pricing passengers coach service in regulated markets. The method implementation has low cost and is suitable to situations where the regulator has no historical economic and financial data to establish the tariffs based on the cost of service. Furthermore, it does not require complex calculations neither is based on unverifiable historical financial or market data. The model draws on the concepts of the model of price-cap regulation. A coefficient of type X-factor in price-cap is used to determine the productivity gains in order to induce future efficiency on the service provision. In this article, the model is applied to a hypothetical case of passenger transportation by bus and thus the Xfactor is defined as an index of industrial activity of passenger coach services. The financial economic literature defines several levels of activity, one of them is the ratio between revenue and net fixed assets. Moreover, the proposed model is used to establish upper and lower limits for the tariff-bid, reducing possible opportunistic behavior at the auction.
\end{abstract}

Key words: pricing of passenger transport by bus, reservation price, price-cap, $x$-factor, revenue for fixed assets.

*Email: pbritto@unb.br.

\section{Recommended Citation}

Britto, P. A. P. and Rocha, C. H. (2013) Determinação do valor da tarifa-leilão do serviço de transporte de passageiros por ônibus: um modelo alternativo. Journal of Transport Literature, vol. 7, n. 3, pp. 177-191.

- JTL/RELIT is a fully electronic, peer-reviewed, open access, international journal focused on emerging transport markets and published by BPTS - Brazilian Transport Planning Society. Website www.transport-literature.org. ISSN 2238-1031.

This paper is downloadable at www.transport-literature.org/open-access. 


\section{Introdução}

As economias modernas desenvolveram um sistema de governança para a prestação de serviços públicos por agentes privados sob regulação de agências reguladoras constituídas especificamente para esse fim. O serviço de transporte interestadual de passageiros por ônibus, com efeito, está estruturado de maneira similar e de forma tal que uma das atribuições mais importantes das agências reguladoras diz respeito à concessão de linhas a operadores privados. Esse artigo se insere nesse contexto ao propor um modelo para a determinação do valor da tarifa-leilão do serviço de transporte de passageiros por ônibus que é implementável em situações de indisponibilidade de dados econômico-financeiros históricos por parte do regulador.

As agências reguladoras são entidades relativamente recentes, tendo sua formatação moderna sido definida a partir da segunda metade da década 80. O surgimento desses órgãos se deu em decorrência natural das privatizações e das concessões para provisão privada de serviços públicos. Nesse contexto, foram instituídas não apenas como fiscalizadores, mas também como intermediários entre as partes envolvidas: estado, empresas privadas e usuários. Cabe às agências reguladoras assegurar o cumprimento das normas que regulamentam os serviços públicos delegados e garantir a execução dos contratos firmados entre o estado e a iniciativa privada.

As concessões e permissões de serviços públicos na América Latina são realizadas por intermédio de leilões (Gausch, 2004). Os leilões de linhas de transporte de passageiros por ônibus, em particular, são planejados para que a firma vencedora seja se proponha a ofertar o serviço, conforme padrões de qualidade pré-estabelecidos, pela menor tarifa a ser cobrada dos usuários. Cabe às autoridades reguladoras estabelecer o valor máximo admitido para a tarifa por ocasião dos leilões - em algumas jurisdições isso é requerido por força de legislação. No caso de competição efetiva pelo mercado, o valor máximo fixado no edital pode vir a ser inócuo.

Em ambientes de assimetria informacional, ou mesmo de má definição dos padrões mínimos de qualidade, capaz de comprometer o monitoramento, por parte do regulador, da qualidade 
do serviço prestado, a competição no certame licitatório pode induzir quedas efetivas na qualidade do serviço que será prestado, incluindo segurança, ou mesmo a interrupção da prestação de serviço por quebra do equilíbrio econômico-financeiro da concessão. Para contornar esse problema pode ser o caso de se fixar um valor mínimo para a tarifa, valor conhecido por preço de reserva do certame licitatório, compatível com o equilíbrio econômico-financeiro da concessão para um nível de qualidade dado. Com isso, seriam atenuadas as implicações decorrentes de comportamentos oportunistas em leilões de serviços públicos (Gausch, 2004).

No Brasil, por exemplo, a delegação na prestação de serviços típicos da indústria do transporte rodoviário interestadual de passageiros, a cargo da Agência Nacional de Transportes Terrestres (ANTT), jamais foi levada a leilão. Apesar de a Agência ter sido incumbida, no ato de sua criação, em 2001, para providenciar a regulação e a regulamentação completa dessa indústria (BRASIL, 2001).

Em geral, as tarifas-leilão de serviços públicos são estabelecidas por meio de modelos de regulação por custo-do-serviço de relativa complexidade (Joskow e Schmalensee, 1985; Viscusi et al, 2005). Por exemplo, para se determinar a tarifa-leilão por meio do modelo de regulação pela taxa de retorno se requer do agente regulador estimativas: (a) do custo médio de capital para o empreendimento; (b) dos fluxos de caixa; (c) do valor dos investimentos e de sua cronologia; e (d) dos riscos subjacentes ao empreendimento.

Para estimar o custo médio de capital do empreendimento, o agente regulador usa os modelos WACC, modelo de custo médio ponderado do capital. O custo do capital próprio é estimado, em geral, a partir do modelo de modelo de precificação de ativos, CAPM. O custo do capital de terceiros envolve o estudo detalhado de fontes de financiamento específicas disponíveis para o empreendimento em questão (Brigham e Houston, 1999; Samanez, 2006).

O modelo WACC exige que seja fixada a estrutura ótima de capital do empreendimento, i.e., que seja fixada a participação relativa do capital próprio e do capital de terceiros no total de capital empregado na concessão, tarefa que envolve, a luz de Modigliani-Miller, algum grau de arbitrariedade. A implementação do CAPM para projetar o custo do capital próprio depende da existência de companhias abertas com características similares às prováveis concessionárias e de um mercado de capitais desenvolvido, condições nem sempre presentes. 
Além disso, como argumentam Fama e French (2004), o CAPM não funciona tão bem empiricamente. O cálculo do custo do capital de terceiros, por seu turno, depende de os prováveis concessionários possuírem títulos de dívida negociados no mercado financeiro, de forma que o custo da dívida pode ser aproximado pela média das taxas interna de retorno desses títulos. Caso a empresa não possua títulos negociados no mercado financeiro, o custo da dívida pode ser obtido através da média dos custos de suas dívidas. Ou ainda, se a empresa possuir títulos de dívida negociados no mercado financeiro e obrigações não negociadas, o custo da dívida seria uma média ponderada dos dois tipos de dívida.

Seguramente, as agências reguladoras dos países da América Latina têm à sua disposição, seja em seus quadros, seja no mercado onde pode contratar consultores independentes, capacidade técnica para empregar modelos complexos de regulação econômica para a determinação da tarifa-leilão. Fato é que se devem estimar tantas tarifas quantas linhas ou lotes de linhas houver para leiloar; esse trabalho pode tomar proporções gigantescas, ferindo sua acuracidade. Esta tarefa torna-se particularmente mais árdua quando não houver dados e informações históricos a respeito do desempenho econômico-financeiro da indústria.

Este artigo propõe um método (modelo) simples e robusto para estabelecer o limite superior e o limite inferior para a tarifa das linhas de ônibus a serem leiloadas. A maior contribuição desse artigo está na proposta de uma metodologia de determinação de preço aplicável sempre que a indústria de transporte de passageiros por ônibus atravessar a primeira rodada de leilão, ainda que sejam não observáveis volumes grandes de dados históricos acerca da atividade, tais como o número de passageiros transportados por linha, as receitas por serviço e os custos discriminados, entre outros.

O artigo está organizado da seguinte forma. A Seção 1 apresenta primeiramente a base conceitual do método proposto para, então, apresentá-lo em substituição aos métodos complexos de determinação da tarifa-leilão do transporte de passageiros por ônibus. A Seção 2 traz uma formulação para os reajustes tarifários e comenta, em breve, sobre a função de acompanhamento do equilíbrio econômico-financeiro da entidade jurídica operadora do transporte de passageiros por ônibus. A Seção 3 encerra o artigo. 


\section{Fundamentação teórica e a regra subjacente}

O esquema de regulação por incentivos conhecido por price cap com fator de produtividade (o fator-X), conforme aponta Makholm (2007), consiste de um esquema de regulação baseado em incentivos correntemente empregado em diversos países e que, sem exceção, requer alguma forma de quantificação de produtividade ou de eficiência.

Esse esquema regulatório estabelece uma trajetória intertemporal para o preço máximo de comercialização do item sem o uso de informações históricas ou contábeis, sendo à firma permitido cobrar preços inferiores ao valor máximo fixado e sendo esse valor máximo revisado periodicamente, em geral para menos, conforme a seguinte expressão:

$$
T A=R P I-X
$$

em que $T A$ é a taxa de aumento do preço-teto, $R P I$ é um índice de inflação e $X$ é o fator de redução do preço real.

Sob um regime de price-cap tal que o representado pela expressão em (1), se a firma regulada for capaz de obter ganhos de produtividade elevados, então ela deverá compartilhar esses ganhos com os consumidores na forma de preços mais baixos ou de modicidade de tarifa. A escolha apropriada de um fator-X é crítica para a sustentabilidade do esquema regulatório. Se o fator-X for muito pequeno, a firma regulada terá lucros excessivos; inversamente, se o fator$\mathrm{X}$ for muito grande, a viabilidade da firma regulada pode ficar comprometida. Dessa forma, a essência de um esquema regulatório do tipo price-cap está na correta escolha do fator-X que, se por um lado oferece um desafio à empresa regulada, por outro, gera benefícios aos consumidores.

Conforme lembram Bernstein e Sappington (1998), o regulador deve fixar um valor para o fator$\mathrm{X}$ de forma a refletir os ganhos esperados de produtividade no setor vis-à-vis os ganhos esperado para a economia como um todo e, ao mesmo tempo, mudanças esperadas nos preços dos insumos, e consequentemente no custo de produção, também do setor regulado em comparação a um índice de preços agregado. Ao proceder dessa forma, o regulador assegura que alterações nos preços relativos dos insumos não contaminem a medição dos ganhos de produtividade. 
A aplicação prática desse esquema envolve uma controvérsia acerca da definição do fator-X. A proposição original empregada por Stephen Littlechild quando da privatização do setor de telecomunicações na Inglaterra, em 1990/91, previa a fixação de uma taxa de crescimento da produtividade que deveria ser perseguida pela firma regulada. Essa taxa deveria ser fixada exante, ou seja, antes do início do interstício regulatório, de forma que o regulador transferiria à firma o ônus de buscar meios e forma alternativas de realizar ganhos de produtividade maior ou igual ao valor fixado no início do interstício. Aplicações posteriores introduziram uma importante modificação nesse esquema com o fator-X sendo fixado ex-post, ou seja, ao final do período regulatório. Sob essa modificação, o fator-X passou a ser uma forma de repartição de ganhos de produtividade já realizados entre a firma e os consumidores. $\mathrm{O}$ esquema subjacente de incentivo à busca de maior eficiência fica modificado, pois agora o prêmio que a firma obtém por ganhos de produtividade em um interstício regulatório é obtido somente durante esse mesmo interstício.

Segundo Makholm (2007), são três os índices mais empregados no mundo para o cálculo desse fator-X em esquemas cuja determinação se dá ao final do interstício regulatório: o índice de Fischer, o índice de Törnqvist e o índice Malmquist. Todos os três constituem aplicações metodológicas alternativas que permitem se estimar ganho de produtividade total dos fatores (PTF) de produção.

Os dois primeiros índices, de Fischer e de Törnqvist, são bastante parecidos entre si e medem a evolução da PTF num intervalo de tempo através da razão de dois índices, de quantidade de produto e de quantidade fatores em cada período. Medem a diferença entre a variação da produção e a variação ponderada do uso de insumos de forma que as alterações de produto não explicadas pelas variações no insumo são atribuídas à ganhos de produtividade. A popularidade dos índices de Fischer e Törnqvist resulta, fundamentalmente, do fato de poderem ser calculados diretamente a partir de dados observados para quantidades e preços, sem a necessidade de se estimar uma função de produção para o setor no período em análise (GriffelTatjé e Lovell, 1996).

A metodologia Malmquist, por seu torno, consiste em calcular alteração na produtividade total dos fatores com base em diferenciais de produtividade em relação a uma fronteira eficiente. A fronteira eficiente, nesse caso, é estimada a partir de métodos deterministas não-paramétricos, tal como o Data Envelopment Analysis (DEA) ou de funções estocásticas paramétricas. (Caves et alli, 1982) 
Em relação aos índices de Fischer e Törnqvist, o índice de Malmquist apresenta a vantagem de não necessitar da suposição da hipótese de maximização do lucro por parte da firma, algo particularmente importante em setores regulados, e de dispensar informações sobre preços dos produtos e de fatores de produção. Além disso, o método de Malmquist permite a decomposição da evolução da PTF em modificações da eficiência produtiva (aproximação ou afastamento em relação à fronteira eficiente) e em alterações tecnológicas (movimentos da fronteira eficiente). A principal limitação desse índice está no fato de ser aplicável apenas para dados em painel, o que exige maior volume de informações (Griffel-Tatjé e Lovell, 1996).

A discussão do price cap apresentada até aqui toma como dado um padrão de qualidade tido como desejável. Conforme já observado, em ambientes de assimetria de informação o nível de qualidade passa também a ser uma variável de decisão na medida que reduções de qualidade podem induzir menores custos. (Sappington, 2005). No caso do transporte rodoviário de passageiros, é fácil perceber que a qualidade do serviço possui diversos atributos de difícil comparação, tais como, por exemplo, a segurança, a pontualidade e o conforto. Ademais, quanto mais atributos tiver o serviço público regulado, mais difícil será para o regulador estabelecer o custo de uma melhora marginal em um destes atributos.

Em se tratando de leilão de concessão, em situações nas quais a qualidade não é verificável, as empresas participantes de um leilão de concessão têm forte incentivo para estimar custos associados à menor qualidade não detectável pelo regulador. Procedendo dessa maneira, as empresas podem ofertar uma tarifa menor e elevar sua chance de vencer a licitação. Tal comportamento é mais atrativo, conforme aponta Gausch (2004) e Gaucsh e Straub (2006), em ambientes institucionais que favorecem a renegociação do contrato de concessão durante a sua vigência - as empresas elevam a qualidade e os custos de provisão do serviço para, posteriormente, obter autorização do regulador para elevar seus preços. Ao regulador cabe empregar meios de contornar esse problema. Uma forma consiste no emprego de fiscalização no caso de qualidade verificável. Outra forma consiste em desenhar o leilão de forma a reduzir o espaço para comportamentos oportunistas. 


\section{O modelo proposto}

A existência de informação acerca do mercado regulado, seja de demanda, seja de custos das empresas que nele atuam, é fundamental para o sucesso a atividade regulatória. Além disso, conforme apontam Salgado e Oliveira (2012), a existência de tais informações é fundamental para a transparência regulatória. No caso de informações dos entes regulados, os autores destacam a dificuldade de obtenção dado que tais entes relutam em fornecê-las ao vislumbrarem oportunidade de ganhos associados à assimetria de informação.

Para a implementação do modelo proposto se supõe a existência de dados históricos contábilfinanceiros das linhas de transporte de passageiros que permitam, entre outros, o cálculo da produtividade na indústria de transporte de passageiros por ônibus. A referência aos dados contábil-financeiros se deve à necessidade de informações críveis, simples e, ao mesmo tempo, com conteúdo informacional útil á tomada de decisão regulatória.

A opção pelo uso de dados contábil-financeiros não é livre de críticas. Existe uma literatura importante que discute as limitações do uso de informações contábeis para fins de gestão, na linha apontada por Johnson e Kaplan (1987) de que a perda de relevância da contabilidade gerencial era resultado da sua subserviência à contabilidade financeira ou societária. Contudo, mais recentemente, como destacam Borinelli et al. (2005), a contabilidade tem conseguido dar resposta às necessidades de informações gerenciais de seus usuários. Nesse sentido, sugere-se o uso dos dados contábeis na medida em que são relativamente fácil de se obter e auditar, ainda que possam apresentar certa deficiência em seu conteúdo informacional.

O modelo proposto estabelece uma banda para a tarifa de referência para uma determinada concessão para exploração de uma dada linha de ônibus, calculada a partir da tarifa atualmente praticada e ajustando-se para diferenciais de produtividade observados.

Seja IA um indicador de atividade qualquer escolhido pelo regulador a partir de informações observáveis e verificáveis. Com base em informações históricas, o regulador calcula os desvios de produtividade para cada tipo de serviço - definidos aqui como linhas comparáveis em termos de distância, taxa média de ocupação, etc. Com efeito, o regulador constrói uma sequência de indicadores para uma linha-padrão a partir de informações de linhas reais comparáveis: 


$$
D I A_{i, L}=\frac{I A^{M A X}-I A_{i, L}}{I A^{M A X}}
$$

Em que $D I A_{i, L}$ é o desvio no indicador de produtividade a empresa, i na linha $\mathrm{L}, I A_{i}$ é o indicador de atividade da empresa $\mathrm{i}$, na linha $\mathrm{L}, I A^{M A X}$ é o indicador de produtividade máxima registrado na linha L. Com efeito, esse modelo se assemelha ao de Malmquist na medida em que considera um desvio da produtividade de uma em relação à produtividade média do setor a que pertence.

Com base nessa seqüência de indicadores associados à expressão (2), o regulador calcula a banda tarifária conforme as regras:

$$
\begin{aligned}
& T_{L}^{M A X}=\left[1-\lambda \times D I A_{L}^{M E ́ D}\right] \times T_{L}^{A T U A L} \\
& T_{L}^{M I N}=\left[1-\lambda \times D I A_{L}^{M A X}\right] \times T_{L}^{A T U A L}
\end{aligned}
$$

Em que $T_{L}^{M A X}$ é o limite superior da banda tarifária para a linha $L, T_{L}^{A T U A L}$ é a tarifa atual praticada pela linha $\mathrm{L}, D I A_{L}^{M E ́ D}$ é o desvio do IA médio em relação ao $I A^{M A X}$, na linha $\mathrm{L}$, $D I A_{L}^{M A X}$ é o desvio do IA mínimo em relação ao $I A^{M A X}$, na linha $\mathrm{L}$ e $\lambda$ é um parâmetro ad hoc fixado pela autoridade reguladora $(0 \leq \lambda \leq 1)$.

O modelo representado pelas expressões em (3) e (4), diferentemente do esquema price-cap, realinha o preço-teto após a observação do ganho de produtividade. Em termos de incentivo à eficiência econômica, há uma diferença óbvia: na medida em que a empresa sabe que seus ganhos serão totalmente apropriados pelo regulador, os incentivos à busca de ganhos de produtividade são menores. Para restaurar os incentivos, se propõe que o regulador assuma o compromisso em deixar com a firma um percentual de seu ganho de produtividade, o parâmetro $\lambda$ no modelo, sendo esse percentual fixado ex-ante.

O índice de atividade pode ser construído com base em informações observáveis e verificáveis de forma que se recomenda o uso de informações contidas nas demonstrações financeiras das atuais empresas de ônibus. A literatura de finanças de empresas traz inúmeros índices de atividade, como em Brigham e Houston (1999) e em Weston e Brigham (1975). 
Sugere-se aqui como índice de atividade $I A$ da indústria de transporte de passageiros por ônibus o giro do imobilizado, indicador de desempenho bastante conhecido na Teoria Contábil (Matarazzo, 2010). O giro do imobilizado, definido como a relação entre receita operacional e imobilizado líquido de uma empresa, mede o número de vezes que os ativos produtivos da empresa transformaram-se em dinheiro, por meio das vendas, em um exercício social.

Com efeito, o índice de atividade é definido como segue:

$$
I A=\frac{\bar{R}}{\overline{\overline{V A}}}
$$

onde $\bar{R}$ é receita líquida de devoluções, abatimentos e impostos, média dos últimos três anos, por exemplo, de um prestador de serviço de transporte de passageiros por ônibus, em análise e $\overline{V A}$ é o valor médio do imobilizado, líquido de sua depreciação acumulada, em reais, desse mesmo prestador, nos últimos três anos.

A partir do índice de atividade calculado conforme a expressão em (5), para todos os prestadores de serviços em uma dada indústria, define-se o maior valor do índice de atividade como $I A=I A^{M A X}$ e o menor valor, como $I A=I A^{M I N}$. Dado que $\bar{R}$ e $\overline{V A}$ são positivos, $I A>0$. No caso de mercados pequenos, com apenas um prestador, pode-se cumprir esse passo segmentando-se por linhas de ônibus.

Portanto, qualquer lance no leilão entre $T_{L}^{M I N}$ e $T_{L}^{M A X}$, inclusive os extremos, seria aceitável. Como pode ser visto o método proposto é simples, de fácil aplicação e não requer: a montagem de fluxo de caixa, a determinação de taxa de desconto (do custo de capital), entre outros quesitos.

Por fim, cabe ressaltar que a metodologia não inviabiliza a concessão de nenhuma linha, ainda que localizada em um mercado geográfico de baixa densidade demográfica. Para ver isso, considere duas linhas com imobilizados similares, mas diferentes níveis de utilização. Se a empresa com menor produtividade for lucrativa, então há espaço para redução da tarifa e é exatamente nesse espaço que o modelo proposto assegura a competição. 


\section{Equilíbrio econômico-financeiro e reajustes tarifários}

Primeiramente, para cada concessão, para uma linha ou para um grupo de linhas, deve ser criada uma entidade jurídica distinta da empresa vencedora. Cabe ao órgão regulador (a) estabelecer os aspectos legais das entidades jurídicas operadoras do transporte rodoviário de passageiros, (b) construir banco de dados que espelhe as demonstrações financeiras dessas entidades e, entre outras coisas, por intermédio dos dados depositados nesse banco, (c) acompanhar o desempenho econômico-financeiro dos operadores.

O acompanhamento da saúde financeira das entidades operadoras do transporte rodoviário de passageiros deve ser informatizado. As entidades preencherão periodicamente, a cada três meses, por exemplo, formulários sitiados no portal da respectiva agência reguladora, para, então, que sejam analisados. O sistema computadorizado de acompanhamento deve funcionar como um sistema do tipo Business Intelligence (BI). Os reajustes da tarifa são necessários principalmente para a manutenção do equilíbrio econômico-financeiro do empreendimento.

Sugere-se que os reajustes tarifários sejam concedidos de acordo com a versão modificada do price-cap - aquela em que o fator-X é obtido a partir da observação do ganho de produtividade observado. Com efeito, a tarifa reajustada será obtida conforme equação a seguir, na qual o índice de atividade definido na expressão em (4) entra como uma proxy para o fator-X:

$$
T_{t+1}=T_{t} \times\left(1+\frac{\left(\Delta I P_{t}-\Delta \overline{I A}_{t}\right)}{100}\right)
$$

Em que $T_{t+1}$ é a tarifa na data $t+1, T_{t}$ é a tarifa em vigor na data $t, \Delta I P_{t}$ é a variação do índice de preços ao consumidor em percentual no período $t$ e $\Delta \overline{I A}_{t}$ é a variação do índice de atividade representativo da indústria em percentual no período $t$ fixado pelo órgão regulador.

Note-se que se a variação do índice de atividade da indústria do transporte rodoviário de passageiros por ônibus no período $t$ for maior (menor) do que a inflação $\left(\Delta I P_{t}\right)$, no mesmo período, a tarifa futura, em $t+1$, cairá (aumentará). Contudo, se a empresa conseguir ganhos de produtividade que vão para além de $\Delta \overline{I A}_{t}$, esses ganhos serão por ela apropriados, estabelecendo o incentivo à busca de eficiência. 
Ademais, esse esquema de reajuste associado à expressão em (6) também induz eficiência dinâmica. Ao comparar o desempenho médio do setor com o de uma empresa particular, gera pressão competitiva: cada empresa buscará ganhos de produtividade superiores às demais, o que tende acelerar os ganhos de produtividade do setor.

\section{Aplicação a um Caso Hipotético}

A título de ilustração da implementação do modelo proposto simula-se a tarifa-leilão de uma linha do transporte intermunicipal de passageiros por ônibus usando dados fictícios. Suponha uma linha em que operam 24 empresas e suponha que os seguintes indicadores de atividade sejam observados:

Tabela 1 - Indicadores de Atividade, Linha-padrão L, 24 empresas.

\begin{tabular}{|llll|}
\hline 3,41 & 3,69 & 2,85 & 3,33 \\
3,33 & 3,64 & 2,35 & 2,81 \\
3,21 & 3,63 & 2,77 & 3,06 \\
3,04 & 3,57 & 3,16 & 2,57 \\
2,72 & 3,04 & 3,08 & 2,86 \\
2,62 & 2,87 & 2,94 & 3,21 \\
\hline Estatísticas Relevantes & & & \\
Média & & 3,07 & \\
Máximo & 3,69 & \\
Mínimo & 2,35 & \\
Desvio Médio (\%) & $17 \%$ & \\
Desvio Máximo (\%) & $36 \%$ & \\
\hline
\end{tabular}

Suponha que a linha que se deseje licitar opera atualmente com uma passagem unitária de $\mathrm{R} \$ 20,00$ e que o regulador estabeleça $\lambda=50 \%$. Com base nas expressões em (3) e (4), tem-se:

$$
\begin{aligned}
& T_{L}^{M A X}=[1-0,5 \times 0,17] \times 20,00=18,30 \\
& T_{L}^{M I N}=[1-0,5 \times 0,36] \times 20,00=16,40
\end{aligned}
$$


Imagine que a tarifa-lance vencedora do leilão seja de $\mathrm{R} \$ 16,95$. Isto representa que os usuários da linha A-B realizarão excedentes. Talvez, em função da queda no preço do ticket, novos usuários sejam levados a usar a linha.

O regulador, a partir de análises dos índices de atividade da indústria estadual do transporte rodoviário de passageiros, estabelece para a linha $\mathrm{A}-\mathrm{B}$ e para linhas semelhantes $\Delta \mathrm{IA}=1,5 \%$, em média. A inflação anual média entre data de início da operação da linha e a época do reajuste tarifário é de $\Delta \mathrm{IP}=4,5 \%$. Portanto, a nova tarifa reajustada, de acordo com a expressão em (6), é igual a $R$ \$ 17,46. Este valor prevalecerá até a data do próximo reajuste tarifário.

\section{Conclusão}

Os leilões de linhas de transporte de passageiros por ônibus são planejados para que a firma vencedora seja aquela que atribua o menor valor para a tarifa a ser cobrada dos usuários. Para estabelecer o valor máximo aceito da tarifa-lance do leilão, podem-se empregar modelos como o da taxa de rentabilidade, o de preços tetos e o de preços com partilha de lucros, entre outros (Mata, 2010). Ocorre que esses métodos requerem um volume expressivo de dados históricos e informações para determinar a tarifa máxima do leilão.

Muitas vezes, não se dispõe de dados históricos para fixar a tarifa do leilão por meio de um de tais modelos. A deficiência de dados históricos econômico-financeiros do transporte de passageiros por ônibus é um problema do Brasil e de outros países latinos americanos, conforme relatam Ospina (2004) e Salgado e Oliveira (2012).

Este artigo oferece um modelo alternativo de precificação da tarifa do transporte rodoviário de passageiros por ônibus. O modelo proposto não requer cálculos e, tampouco, dados históricos de relativa complexidade. Enfim, o modelo apresentado neste artigo é de fácil cômputo e atende às localidades que estão prestes a licitar os serviços do transporte por ônibus, mas que não dispõem de dados econômico-financeiros históricos complexos para estabelecer o rol de tarifas. Esse é o caso de muitos estados e municípios brasileiros e de muitos países da América Latina que adotaram modelos de concessão e permissão de serviços públicos. 
O modelo proposto se vale dos conceitos do denominado modelo price-cap. Um coeficiente do tipo fator-X, no price-cap, é utilizado para a determinação da tarifa. Esse fator é representado por um índice de atividade da indústria ou da própria linha de ônibus, se houver disponibilidade de dados. Uma vantagem a se destacar dessa opção por um modelo baseado no princípio price-cap é o de que permite uma regulação de baixo custo na medida em que é pouco intensiva em informações históricas quando se compara com modelos de regulação por custo de serviço.

No modelo proposto, os limites mínimo e máximo calculados para tarifa-leilão tomam por base informações simples e de fácil verificação, na medida em que podem ser extraídas facilmente das demonstrações contábeis das empresas. Ademais, a comparação desses dados permite que se identifique outliers, índices muito diferentes que podem ser ou retirados da análise ou indicativos de auditorias futuras por parte do regulador. A escolha do índice de atividade baseada no giro do ativo imobilizado líquido encontra paralelo na literatura de economia financeira (Brigham e Houston, 1999; Weston e Brigham, 1975).

Por fim, cabe mencionar que existem críticas ao uso de dados contábeis para estudos comportamentais de empresas (ver Borinelli et all, 2005). No caso em tela, a proposta metodológica se aplica a setores sujeitos à escassez de dados observáveis e verificáveis, de forma que o uso das informações contábeis surge como último recurso. Ademais, considerando que parte dessas críticas advém do regime de apropriação de valor por competência, acredita-se que a característica dinâmica da metodologia capturada pelas revisões periódicas, pode mitigar esse problema.

\section{Referências}

Armstrong, M., Cowan, S. e Vickers, J. (1994) Regulatory reform: economic analysis and British experience. Cambridge, MA: The MIT Press.

Bernstein, J. e Sappington, D. (1998) Setting the X Factor in Price Cap Regulation Plans. NBER Working Paper Series n. 6622.

BRASIL. (2001) Lei N. 10.233, de 5 de Junho de 2001. Dispõe sobre a reestruturação dos transportes aquaviário e terrestre, e dá outras providências.

Borinelli, M. L., Soutes, D., Zan, A. e Frezatti, F. (2005) Relevance lost - uma releitura. In: Anais do $5^{\circ}$ Congresso USP de Controladoria e Contabilidade, São Paulo. São Paulo: FEA/USP, 2005. CD-ROM. 
Brigham, E. e Houston, J. (1999) Fundamentos da moderna administração financeira. Rio de Janeiro: Campus.

Caves, D., Christensen, L. e Diewert, W. (1982) The economic theory of index numbers and the measurement of input, output, and productivity. Econometrica vol. 50, n. 6, pp. 1393-1414.

Church, J e Ware, R. (2000) Industrial organization: A strategic approach. New York: McGraw-Hill.

Fama, E. e French, K. (2004) The capital asset pricing model: theory and evidence. Journal of Economic Perpectives, vol. 18, n. 3, pp. 25-46.

Gatti, S. (2008) Project finance in theory and practice. New York: Academic Press.

Gausch, J. (2004) Granting and renegotiating infrastructure concessions. Doing it right. Washington, D.C.: The World Bank.

Gausch, J. e Straub, S. (2006) Renegotiation of infrastructure concessions: an overview. Annals of Public and Cooperative Economics, vol. 77, n. 4, pp. 479-493.

Grifell-Tatjé, E. e Lovell, C. (1996) Deregulation and productivity decline: the case of spanish saving banks. European Economic Review, vol. 40, pp. 1281-1303.

Johnson, H. e Kaplan, S. (1987) Relevance lost : the rise and fall of management accounting. Harvard Business School Press.

Joskow, P. e Schamalensee, R. (1985) Incentive regulation for electric utilities. Yale Journal on Regulation, vol.4, pp. 1-49.

Makholm, J. Elusive efficiency and the $\mathrm{X}$-factor in incentive regulation: the Törnqvist $\mathrm{v}$. DEA/Malquist dispute. In: Voll, S.P., e King, M.K. (Eds.), The Line in the Sand: The Shifting Boundaries Between Markets and Regulation in Network Industries. National Economic Research Associates, White Plains: New York, pp. 95-115.

Mata, J. (2010) Economia da empresa. Lisboa: Fundação Calouste Gulbenkian.

Matarazzo, D. (2010) Análise de balanços: abordagem gerencial. São Paulo: Atlas.

Ospina, G. (2004) Colombia: desarrollo económico reciente en infraestructura. Santiago: Transport Unit, World Bank (ECLAC).

Salgado, L. H. e Oliveira, A. V. M. (2012) Assimetrias de informação e o provimento obrigatório de dados de firmas reguladas: estudo de caso do transporte aéreo. Journal of Transport Literature, vol. 6, n. 3, pp. 204-238

Samanez, C. (2006) Gestão de investimentos e geração de valor. São Paulo: Pearson.

Santos, R. (2004) A diversidade regional e o dilema do modelo regulatório na telefonia fixa do Brasil. Nova Economia, vol. 14, n. 1, pp. 153-182.

Sappington, D. (2005) Regulating service quality: a survey. Journal of Regulatory Economics, vol. 27, n. 2, pp. 123-154.

Viscusi, W., Harrington, J. e Vernon, J. (2005) Economics of regulation and antitrust. Cambridge, MA: MIT Press.

Weston, J. e Brigham, E. (1975) Managerial finance. London: Dryden. 